\title{
Research on the advantages of in situ investigation of air quality parameters by means of environmental auto laboratories
}

\author{
Angelica-Nicoleta Călămar ${ }^{*}$, Lorand Toth, Sorin Simion, Marius Kovacs \\ National Institute for Research and Development in Mine Safety and Protection to Explosion - \\ INSEMEX Petroşani, 32-34 G-ral Vasile Milea Street, Postcode: 332047, Petroşani, Hunedoara \\ County, Romania
}

\begin{abstract}
Air quality monitoring involves a series of quantitative and qualitative observation and measurement of several air condition indicators, such as concentrations of air components. For this purpose, it is necessary to take several samples of air (gases, dusts, VOCs, physicochemical agents) with specialized equipment having the lowest measuring ranges, sometimes going up to ppt concentrations. At present, most environmental laboratories use individual equipment / analysers for each analysed environmental parameter or carry out sampling in an absorbent / adsorbent environment, and then analyse compounds in laboratories. The current paper presents the advantages of sampling / analysis of environmental compounds with the help of mobile environmental laboratories which allow in situ sampling and analysis of several air quality indicators and fast identification of polluted areas by simultaneous measurements of several samples and strategic and tactical decision making to confute pollution and prevent it. Having a mobile environmental laboratory is equivalent to using the latest concepts and methods of in-situ environmental parameter analysis technology to monitor environmental quality, securing the acquisition and processing of data but requiring specific knowledge in the field to transmit information as accurate and rapid as possible to the beneficiary or environmental authority.
\end{abstract}

\section{Introduction}

Research and services carried out by the Laboratory for Environmental Protection within NIRD INSEMEX Petroşani is dedicated mainly to the control of air pollution. Development and validation of new methods for measuring pollutants present in ambient air, but also in air inside buildings / workplaces is one of our major concerns. In this respect, the alignment of the research laboratory's infrastructure with European and international requirements, the desire to diversify and expand the area of laboratory's

* Corresponding author: angela.calamar@insemex.ro 
activity, as well as development of the capacity to perform expertise of environmental events, led to suggestion of a project for the acquisition of a mobile environmental laboratory.

The purpose of the paper is to demonstrate the usefulness / advantages of owning a mobile laboratory compared to field sampling followed by laboratory analysis.

There are many situations [1,2] where certain analyses (especially water and gas samples) can only be performed by certain equipment (e.g. ion chromatograph, gas chromatograph coupled with mass spectrometer, inductively coupled plasma optical spectrometers, etc.) for accuracy and with high certainty, but if we are talking about the most frequent parameters for air quality (according to Law 104/2011), most can be measured by using analysers fitted on a mobile laboratory.

Of particular importance is the precise or clear knowledge of the investigation's purpose. Generally speaking, an environmental analysis considers the following objectives $[2,3,4]$ :

- establishing the current state of environmental components;

- establishing local and temporal trends;

- establishing pollution sources;

- measurements to estimate potential risks, environmental impact, impairments etc.

Currently, in Romania, there are few mobile environmental laboratories, and most of them are equipped quite briefly, primarily due to the high costs of the equipment. In this sense, there are researches carried out with the help of mobile environmental laboratories [5] which have proven to be very effective and which encourage its acquisition.

\section{Analysis of the requirements and methods related to testing the environmental parameters}

Environmental pollution control includes issues of detection and measurement of pollutants, management of long-term control and surveillance systems and enactment of rules on maximum permissible limits for pollutants.

Sampling air aims at analysis of gaseous compounds or pollutant compounds present in the atmosphere as solid particles [6,7]. Therefore, sampling methods differ depending on the type of compound analysed in the collected air sample.

For the analysis of some pollutants, all qualitative and quantitative methods of chemistry can be applied taking into account the following selection criteria: the smallest detection limit, increased sensitivity, accuracy, speed. However, since at the end of the test the results obtained must be compared with the maximum admissible values measured by a particular method, it becomes almost a necessity that the analysis of various pollutants is carried out by the method set out by standards. This is mandatory in case of environmental audits, impact studies or measurements made to solve litigation situations (comparison of results between different laboratories specialized in different types of environmental analyses and the central environmental reference laboratory). In conclusion, a pertinent analysis of environmental components (air, water, soil) involves the use of appropriate sampling techniques (to ensure representativeness of the selected sample), verified methods of analysis / measurement and a correct interpretation of results.

Identification and measurement of environmental pollution [3] can be achieved in several ways:

- organoleptic analyses;

- use of biological indicators;

- laboratory analyses of pollutants.

Choosing the analysis method for different pollutants depends on: toxicity and concentration of pollutants, quantity emitted in the environment by normal functioning of enterprises, chemistry of pollutants, etc. Laboratory analyses must be preceded by a special sampling 
technique and, where needed, appropriate processing. A sampling of air polluting substances must be representative, that is to say, to have the same qualities and characteristics as the environment from which it was collected, to observe the actual composition of the pollutants, both physically (particle size) and in terms of chemical composition.

Taking samples is also an important issue. First of all, it is necessary to establish which places and timeframes are best suited for taking representative samples. For example, in case of atmospheric pollution research, whole air samples can be taken, aerosols can be extracted by filtration only, active or inert support deposits can be analysed, or direct identification and measurement of the harmful agent can be used.

In the case of water, we have the possibility to take filtered or unfiltered water, downstream or upstream of the point of interest, to study banks, etc. The sampling time must be correlated with the industrial or public activity period generating the respective contaminant, the critical atmospheric conditions (e.g. atmospheric inversion), etc. There are also technical details such as sample volume, sampling depth (water) respectively height (air), position on water, banks, confluences, spillways, etc. [8]

For observation of industrial pollutants, sampling time starts from the beginning of the industrial activity until its completion. It is, however, likely that this environmental observation should be extended beyond the industrial operating period, because during industrial breaks, the pollutant could be discharged from technological tanks [4,9]. Similarly, measurements during industrial breaks give us the opportunity to see what is the air and water self-purification capacity, or eventually to read other sources for the same pollutant [10].

\section{Advantages of in situ investigation of air quality parameters by means of environmental auto laboratories}

For the correct assessment of a polluted or potentially polluted area, sampling is performed simultaneously because (especially gaseous) contaminant spread relatively uniformly across the surface, depending on wind speed. To do so, several analysers are required to work in parallel, so a mobile environmental laboratory offers this possibility, if properly endowed. Also, the height at which air samples are taken is another important factor, the auto-laboratory also offering this possibility, the use of certain supports/props for proper sampling not being necessary.

The choice of equipment included in the auto-laboratory is made taking into account, first of all, the market requirements (environmental quality parameters that we want to analyse) and the applicable legislation regarding the measurement of certain parameters.

\section{Benefits:}

Optimizing the effectiveness of detection work - the operator has at his disposal all the necessary tools, in situ; the ability to charge their batteries, ensuring that all equipment is ready for use at any time

Enhanced equipment protection - Professional storage options within the autolaboratory help protect the equipment against damage during transport, lengthening the lifespan. Moreover, the danger of losing or looking for small accessories such as connecting magnets, connecting cables, headphones or antennas is minimized by permanently storing them in the same place.

Immediate advanced in situ data assessment - offers the possibility to analyse measurement data in situ, immediately after sampling, which saves and improves working time, allowing more operations to be performed in a shorter time. By conventional methods, evaluation of some data was only possible after returning to the laboratory. As the workspace can also be equipped with an air conditioning system, operators have all the facilities and comfort of a mobile laboratory: a place for studying site plans and weather conditions, assessing measurement data and planning the next steps. 
A safe work environment for operators - making measurements at night (e.g. dust, noise, etc.) or in heavy traffic areas requires increased protection for operators. The office compartment allows data to be evaluated in a secure environment.

Moreover, high visibility of the auto-laboratory draws the attention of other participants to traffic in the area where this activity is carried out, ensuring increased protection.

All auto-laboratories are divided into two / three distinct compartments, which may or may not be separated by partition walls: the driver's compartment, the office / equipment calibration compartment and equipment compartment. In this way, the vehicle is transformed into a true loss detection unit. Auto-laboratories have thermally insulated walls and ceilings, and the floor is made of wood covered by sturdy and durable PVC, specifically designed for sustained work. For reasons of safety during transport, it is recommended to separate the driver's compartment from the other side of the vehicle, through a wall.

\section{Equipment compartment}

The storage compartment is made of robust, optionally partially washable materials. Metal shelve systems provide enough storage space for all the equipment. Special fastening systems secure both equipment and standard gas cylinders during transport. The compartment may also be provided with power sockets to charge the equipment.

The additional lighting system provides the light required for work in any conditions, day and night. Also, in this compartment other filters, tripods, water and soil samplers, etc., can be stored, useful in daily in situ activity.

The mobile laboratory is extremely compact and can be perfectly adapted to narrow streets, with the equipment configurable in agreement with the user.

After carrying out air quality analyses in different areas (case studies) with the mobile environmental laboratory, economic operators will be able to more rapidly establish a plan for measures to reduce emissions and disperse hazardous substances in environment, adapting production methods and investing in processes that improve environmental performance.
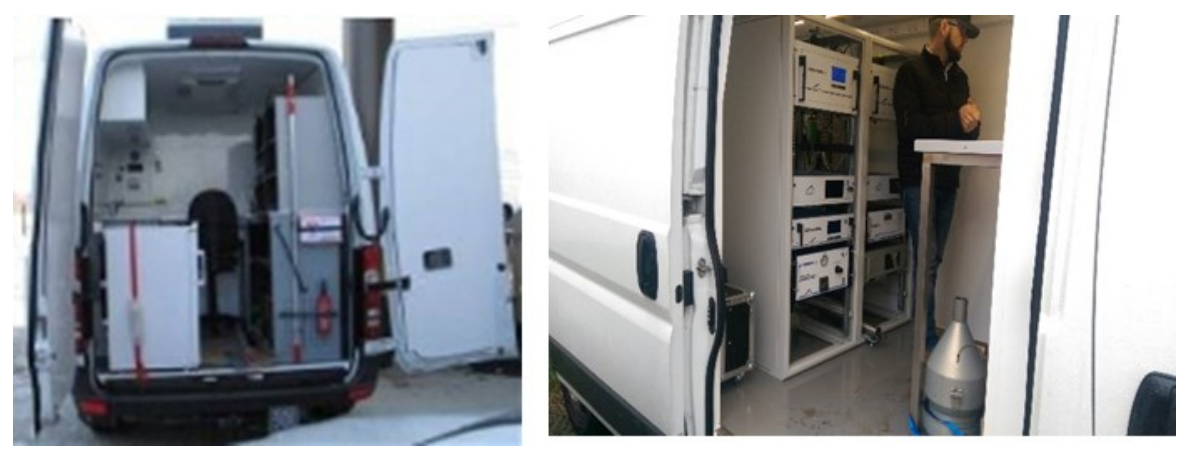

Fig. 1. Mobile environmental laboratory

\section{Conclusions}

The study of pollution characteristic parameters, as well as the factors influencing their generation lead to increased expertise in this field, extension of the knowledge field regarding the pollution phenomenon generated in different industrial areas, to framing protection measures, as well as to improvement of methods for measuring pollutant-specific parameters.

Aligned to the most modern and new techniques in the field, the equipment endowing the auto-laboratory provides the facilities for fast measurement / monitoring of the physicalchemical indicators and for fast forecasting of accidental pollution situations. It also offers the 
possibility of in-situ measurement of a large number of indicators of environmental components and strategic and tactical decisions to combat and prevent pollution.

Fast traveling speed for measurements and estimation of pollutant concentrations leads to finding optimal solutions to prevent and mitigate the effects of accidental pollution and natural disasters.

Through the advanced GIS platform and communication capabilities, it is possible to quickly create forecast maps, the information obtained contributing to establishing new databases that will generate and sustain the research themes for the expansion and diversification of activities.

In conclusion, having a mobile environmental laboratory by research institutes and / or authorities in the field of environmental protection (e.g. Territorial Environmental Protection Agencies) presents a great advantage first and foremost in the event of accidental pollution due to the rapid movement in the field, offering the possibility of simultaneously determining a large number of air quality indicators in situ and quickly identifying the polluted area in order to establish optimal solutions for preventing and mitigating the effects of pollution.

This paper was developed within the Nucleu-Programme, carried out with the support of MCI, project no. PN-19-21-01-01, entitled" Modernization of the research infrastructure for complete in situ investigation of both physical and chemical quality parameters of environmental components within household waste deposits and work environments in order to increase safety and health at work".

\section{References}

1. A. N. Călămar, A. Simion., L. Toth, S. Simion, C. Nicolescu, Improving the method of calculating the ecological footprint generated by road traffic - Case study, Environmental Engineering and Management Journal, Vol.18, No. 4, 781-789, (2019)

2. A. N. Călămar, A.G. Găman, D. Pupăzan, L. Toth., I. Kovacs., Analysis of environmental components by monitoring gas concentrations in the environment, Environmental Engineering and Management Journal, 16, 1249-1256, (2017)

3. J.G. Canadell, D.Le Quéré, M.R. Raupach, C.R. Field, E. Buitenhuis, P. Ciais, T.J. Conway, N.P. Gillett, R.A. Houghton, G. Marland, Contributions to accelerating atmospheric $\mathrm{CO}_{2}$ growth from economic activity, carbon intensity, and efficiency of natural sinks, Proceedings of the National Academy of Sciences, 104, 18866-18870, (2007)

4. E. Ghicioi, G.A. Găman, N. Vlasin, V.M. Păsculescu, D. Gabor, Prevention of accidental pollution with combustion gases after the occurrence of explosions, Environmental Engineering and Management Journal, 16, 1289-1294, (2017)

5. Ionel I., Popescu F. (2009) - - Research and development in the field of environmental protection. Analysis of air quality in the municipality of Timisoara

6. A. Irimia, G. A.Găman, D. Pupăzan, C. Ilie, C. Nicolescu, Use of drones in support of rescue interventions teams in toxic/flammable/explosive environments, Environmental Engineering and Management Journal, Vol.18, No. 4, 831-839, (2019)

7. L. Toth, A. Călămar, A. Irimia, S. Simion, A. Simion, Research on aquatic pollution level of Maleia river by simulation in computational fluid dynamics, Environmental Engineering and Management Journal, Vol.18, No. 4, 935-944, (2019)

8. L. Toth, A. Călămar, A. Irimia, S.Simion, A. Simion, Research on aquatic pollution level of Maleia river by simulation in computational fluid dynamics, Environmental Engineering and Management Journal, Vol.18, No. 4, 935-944, (2019)

9. V. M. Păsculescu, N.I. Vlasin, Ghicioi, G. D. Florea, M. C. Şuvar, New tools for estimating the extent of hazardous areas generated by gas leak explosions, Environmental Engineering and Management Journal, Vol.18, No. 4, 889-90, (2019)

10. G. Băbuț, R. I. Moraru, C. Dura, Conceptual and methodological Framework for Risk Analysis and Evaluation on Seveso Industrial Sites (I) Risk Evaluation Terminology, Objectives and Stages, Quality - Acces to Success Journal, Vol. 16 (145), pp. 111-116, (2015) 